\title{
Phytochemical analysis and antimicrobial activity of adhatoda vasica leaves
}

\author{
Qammer Shahzad ${ }^{1}$, Shehla Sammi ${ }^{1}$, Abid Mehmood ${ }^{2 *}$, Khalid \\ Naveed $^{2}$, Kamran Azeem², Ahmed Ayub ${ }^{3}$, Muhammad Hassaan ${ }^{3}$, \\ Mehak Hussain ${ }^{4}$, Qasim Ayub ${ }^{3}$ and Osama Shokat ${ }^{3}$ \\ 1. Department of Food Science and Technology, The University of Haripur, KPK-Pakistan \\ 2. Department of Agronomy, The University of Haripur, KPK-Pakistan \\ 3. Department of Horticulture, The University of Haripur, KPK-Pakistan \\ 4. Department of Microbiology, The University of Haripur-Pakistan \\ *Corresponding author's email: abidawan1990@gmail.com
}

Citation

Qammer Shahzad, Shehla Sammi, Abid Mehmood, Khalid Naveed, Kamran Azeem, Ahmed Ayub, Muhammad Hassaan, Mehak Hussain, Qasim Ayub and Osama Shokat. Phytochemical analysis and antimicrobial activity of adhatoda vasica leaves. Pure and Applied Biology. Vol. 9, Issue 2, pp1654-1661.

http://dx.doi.org/10.19045/bspab.2020.90174

\begin{tabular}{llll}
\hline \hline Received: 00/12/2019 & Revised: 00/02/2020 & Accepted: 00/03/2020 & Online First: 24/03/2020 \\
\hline \hline
\end{tabular}

\section{Abstract}

The experiment was conducted to estimate the phytochemical and antibacterial activity in Adhatoda vasica during the year 2018. The plant samples were collected from the Khanpur valley in fresh forms and were processed in the Food Science and Technology Laboratory The University of Haripur for further chemical analysis. Antimicrobial activity of Adhatodavasica was tested against various gram positive and gram negative bacterial strains. Different phytochemicals compounds i.e. Alkaloids, Steriods, Flavonoids, Terpenoids, Tannins Extract, Saponins, and Glycosides were investigated in the experiment. Highest antimicrobial activity was recorded in case of gram positive bacteria. Leaf extracts of Adhatodavasica leaves extract would be replacement to synthetic/aritificial antimicrobial agents and needs further studies and clinical trials. The phytochemical screening indicated presence of secondary metabolites such as alkaloid, flavonoids, tannins and phenol in both extracts making it to have antibacterial potentials. Extract showed remarkable activity against the growth of the selected bacteria The presence of these phytochemicals may lead to the conclusion that Adhatodavasica plants can be used as medicine for treating different diseases.

Keywords: Adhatodavasica; Antibacterial activity; Escherichia coli; Phytochemicals;

\section{Staphylococcus aureus}

\section{Introduction}

Adhatoda vasica commonly known as Vasaka, Baker or Malabar Nut belongs to Acanthaceae family [1]. It is evergreen plant ( $1.0 \mathrm{~m}$ to $2.5 \mathrm{~m}$ height) having bitter taste and unplesent smell. It has approximately height of 1 to $2.5 \mathrm{~m}$ [2]. The leaves and flowers of this plant are extensively used for curing asthma, cough, cold, expectorant and antispasmodic. A.Vasica reported to prevent oxidative damage of carbon tetrachloride induced hepatotoxic effect in rats. [3] accounted the highest amount of phenolic compounds with scavenges the free radicals and exhibits greatest antioxidant activity. The positive effect of gamma irradiation on the natural antioxidants of A.Vasica showed release of phenolic compounds [4]. The ethanolic extract of $A$. vasica showed high antioxidant activity with cytoprotective potential in cell culture [5]. Interestingly, 
the methanolic and aqueous extract of $A$. vasica has potential phytochemical composition of flavonoids, phenols with antioxidant and cytotoxic effect [6]. Recently, [7] evaluated pharmacological screening of leaf extract of $A$. vasica against dysentery and diarrhea due to presence of chemical compounds tannins, alkaloids, saponins and flavonoids.

Many plant species posses antioxidant effects and can be used for medicinal purposes. Adhatoda is the specie widely distributed throughout the world. This species is available in Pakistan and particularly in Khyber Pakhtunkhwa region [8]. Hence chemical analysis of Adhatoda vasica is of immense intrest to validate its use in traditional medicine for the cure of many aliments and to find its active principles by chracterisation and isolation of its components. The screening of different phytochemicals of Adhatodavasica can help in detection of new active compounds.

\section{Materials and methods}

The present study was conducted in Food Science and Technology laboratory, The University of Haripur, Khyber Pakhtunkhwa, Pakistan during 2018 to find out the antimicrobial acitivity of Adhatoda vasica along with its phytochemical analysis properties. Fresh leaves of Adhatoda vasica were collected from Khanpur valley of District Haripur, Hazara. Leaves were carried to Food Science and Technology Laboratory for analysis. The leaves were washed thoroughly with tap water in oder to remove any dust and other unwanted particules. Leaves were then air dried for 25 days at room temperature and then grounded with an electric grinder to obtain fine powder. About $100 \mathrm{~g}$ of powdered leaves were transferred into round bottom flask and $750 \mathrm{~mL}$ ethanol \& $250 \mathrm{ml}$ chloroform were added respectively and placed in dark for $72 \mathrm{hrs}$ with occasional stirring. The extract was filtered with whatman filter paper no 4 . The filtrates were then passed through rotary evaporator at a temperature of $45^{\circ} \mathrm{C}$ followed by drying in a desiccator. The gel like crude extracts were stored in refrigerator for further analysis.

\section{Analysis of phytochemical}

Leaf extracts of Adhatodavasica were then subjected to regular phytochemical analyses to uncover the presence or absence of following phytochemicals alkaloids, steroids, flavonoids, Terpenoids, Tannins Extract, Saponins and Glycosides [9-11].

\section{Antibacterial activity assay}

Anti-microbial activity of Adhatodavasica was assessed by using Disc Diffusion Method [12]. Four different bacterial strains were collected from Microbiology Lab, The University of Haripur. Pure cultures were sub cultured in mullor hanton agar as suggested by [13]. The plates were pored with $15 \mathrm{ml}$ of MüllerHinton agar. These plates were kept for 5 min to solidify. Adhatodavasica extracts were then loaded on $5 \mathrm{~mm}$ sterial individual disc. These loaded discs were then positioned on top of medium and allowed to diffuse with each other for $5 \mathrm{~min}$. Later on these plates were kept in incubator at $37^{\circ} \mathrm{C}$ for $24 \mathrm{~h}$. Same solvent was used for preparation of negative control whereas positive control was gentamycine $(10 \mu \mathrm{g} /$ disc $)$. Incubation zones were measured at the end of the incubation using transparent ruler in millimeters.

\section{Results and discussion}

\section{Phytochemical analysis}

The leaf extracts (ethanol, chloroform) of A. vasica have been analyzed for the presence of qualitative phytochemicals. Qualitative phytochemical analysis based on the methods described by [14]. During the analysis, these extaracts were analyzed for Steroids, Tannin, Saponin, Anthocyanin, Coumarins, Alkaloids, Proteins, Amino acids, Diterpenes, Phytosterol, Phenol, Leucoanthocyanin ,Cardial glycosides and Flavonoids (Table 1). It can be observed from (Fig. 1) that chloroform extactrs were unable to show 
the presence of alkoilods while ethanol was proved to be the suitable medium for extraction of alkaloids from $A$. vasica leaves. Alkaloids are proven to cause the benefical biological compound for human health and is important part of diet for ages. Recently, it is used as supplements and pharmaceuticals and in other applications in human life. Moreover, they showed the potential for organic synthesis for searching new semisynthetic and synthetic compounds with possibly better biological activity in controlling and preventing many disease. than parent compounds [15]. From (Fig. 2), it is observed that ethanolic extraction method failed to extract steroids from A. Vasica leaves while chloroform as solvent proved to extract these phytosterols may also act as precursors for the de novo biosynthesis of steroid hormones [16].. Flavonoids, terpenoids and saponins (Fig. 3, 4 \& 5) were present in both extracts which shows promising capabilities of both extracts for prevention and treatment of many degenerative diseases. Tannins are water soluble compounds which is an important raw material for sustainable green industries such as leather, feed, fisheries, beverages, etc [17]. (Fig. 6) showewd that these water soluble compounds can be extracted by using chloroform as a solvent while ethanol has been showed no efficacy in extraction. Glycosides (Cardiac glycoside) are imporatant for increasing the output force of the heart and increase its rate of contractions by acting on the cellular sodium-potassium ATPase pump [18] which were present in ethanolic extracts while chloroform was unable to extract these (Fig. 7) showed presence in ethanolic extracts. The results also showed the antibacterial activity of these leaf extraxcts of Adhatodavasica against various pathogens (Fig. 8, $9 \&$ 10). Tannis are well documented to exhibit the biologically activive compounds against $E$. coli and S. aureus [19]. Results obtained from this study indicates that by using agar-well diffusion method, pure ethanolic extracts od $A$. vasica leaves showed maximum antimicrobial effects against the tested bacteria. Therefore current study also provided a justification of using ethanolic extraction method to obtain phytochemicals which can sway the disease causing pathogens [20]. Same results were also observed by earlier reserachers, who noted that major portion of medicinal plants have least effectiveness againt gram negative as compared to gram positive organisms [21]. Chloroform and ethanolic extracts of $A$. vasica leaves have a potential antibacterial activity against bacterial pathogens and to cure infections caused by bacterial such as $E$. coli, S. aureus and $S$. pyogenes. Nevertheless, the result in this study could also serve as a basis for more investigations on the plant, A. vasica and its antimicrobial capabilities.

Table 1. Phytochemical analysis of $A$. vasica leaves

\begin{tabular}{|c|c|c|c|}
\hline S. No. & Phytochemicals & $\begin{array}{c}\text { Chloroform Extract } \\
\text { [+ means Present; - means } \\
\text { Absent] }\end{array}$ & $\begin{array}{c}\text { Ethanol Extract } \\
\text { [+ means Present; - means } \\
\text { Absent] }\end{array}$ \\
\hline 1 & Alkaloids & - & + \\
\hline 2 & Wagner's & + & + \\
\hline 3 & Steroids & + & + \\
\hline 4 & Flavonoids & + & - \\
\hline & Terpenoids & + & + \\
\hline 5 & Salkowski & + & + \\
\hline 6 & Tannins Extract & & + \\
\hline 7 & Saponins & - & \\
\hline & Cardiac glycoside (Keller- & & + \\
\hline
\end{tabular}


a)

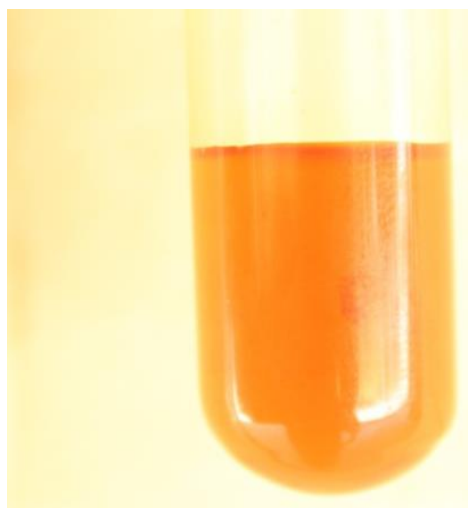

b)

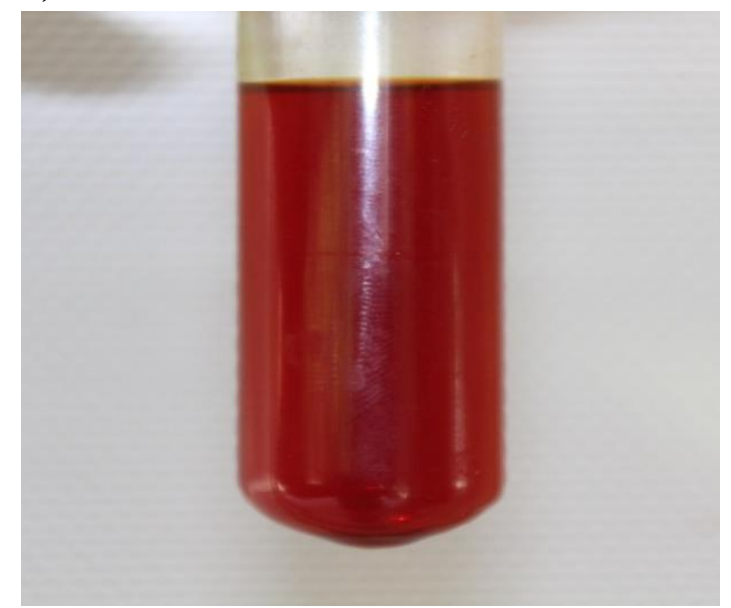

Figure 1. Alkaloids Wagner's Test of (a) chloroform (Negative) and (b) ethanolic (Positive) extracts

(a)

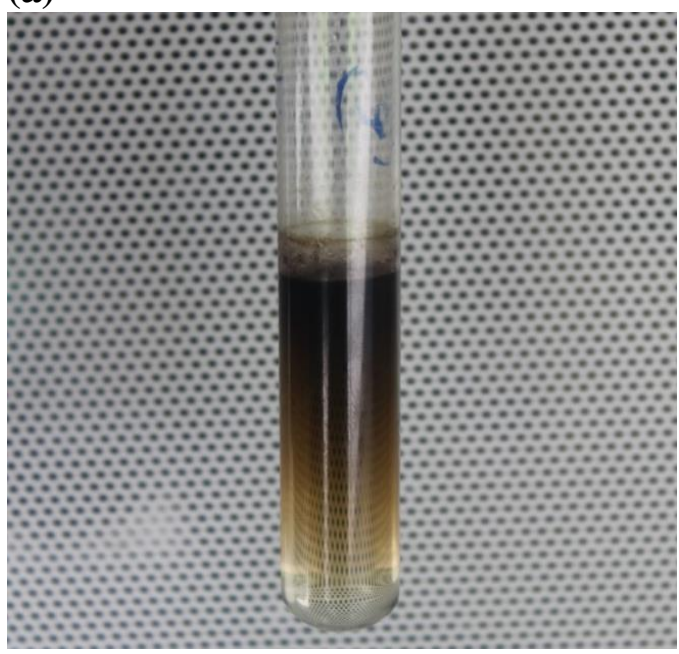

(b)

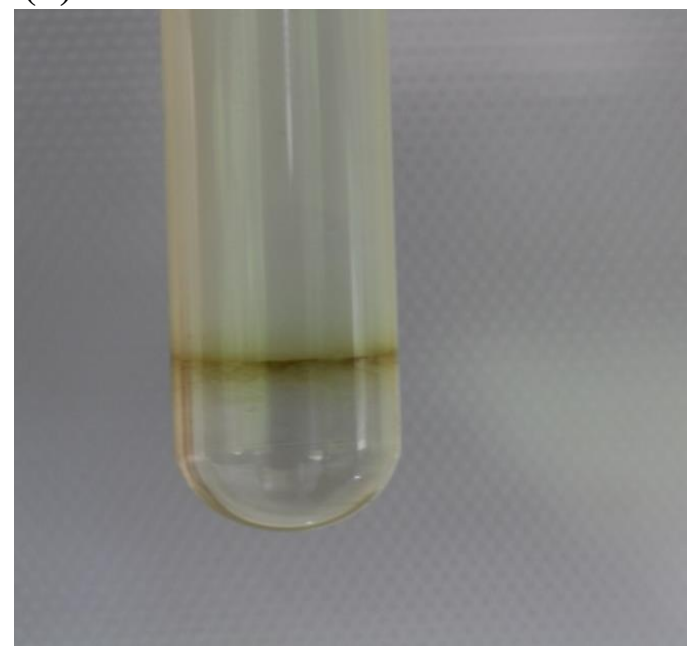

Figure 2. Steroid Test of (a) chloroform (Positive) and (b) ethanolic (Nagative) extracts

(a)

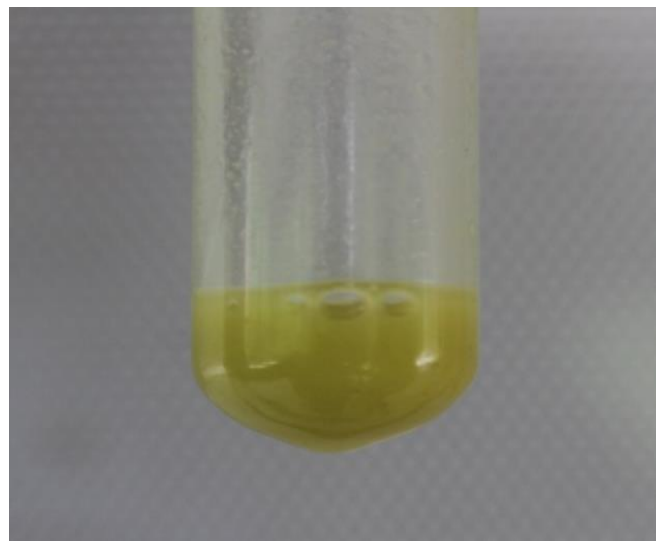

Positive

Figure 3. Flavonoid Test of (a) chloroform (Positive) and (b) ethanolic (Positive) extracts (b)

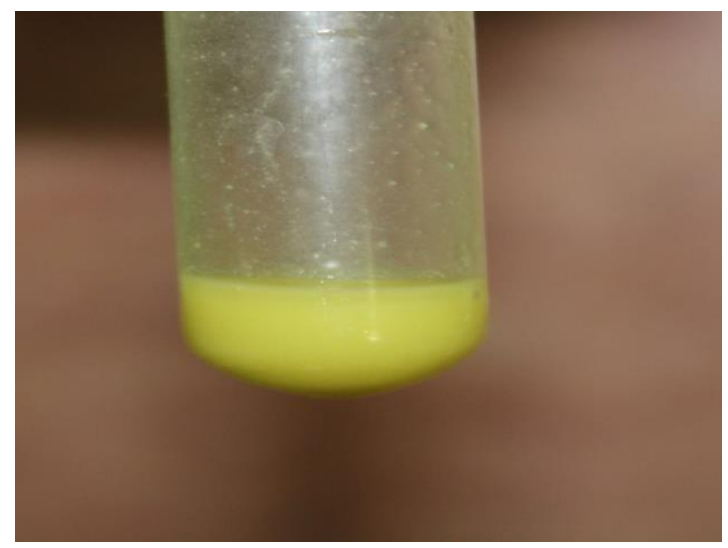

Positive 
(a)

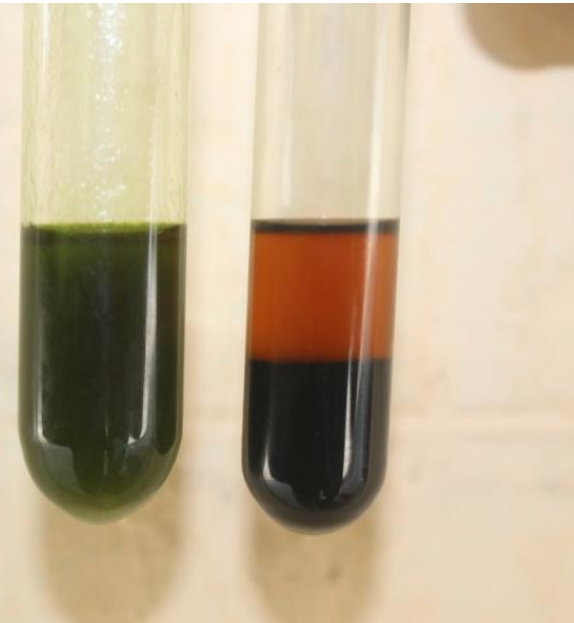

(b)

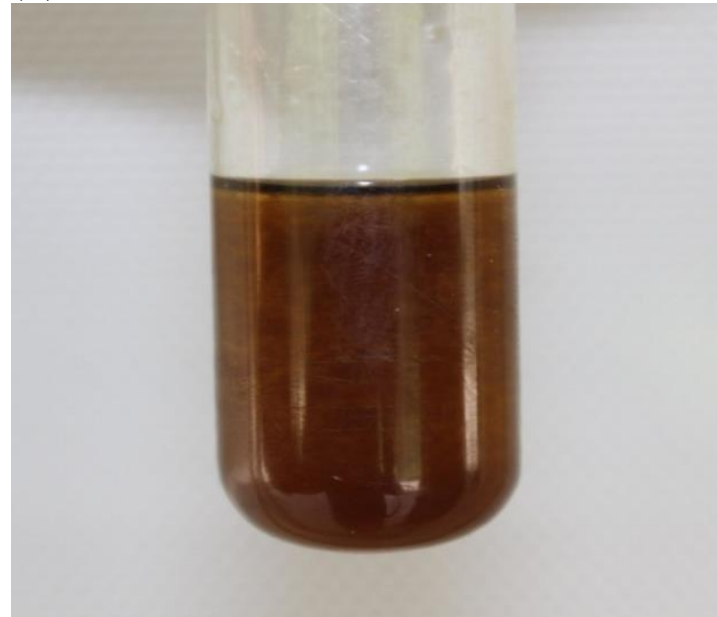

Figure 4. Terpenoids(Phtosterol) Salkowski's Test of (a) chloroform (Positive) and (b) ethanolic (Positive) extracts

(a)

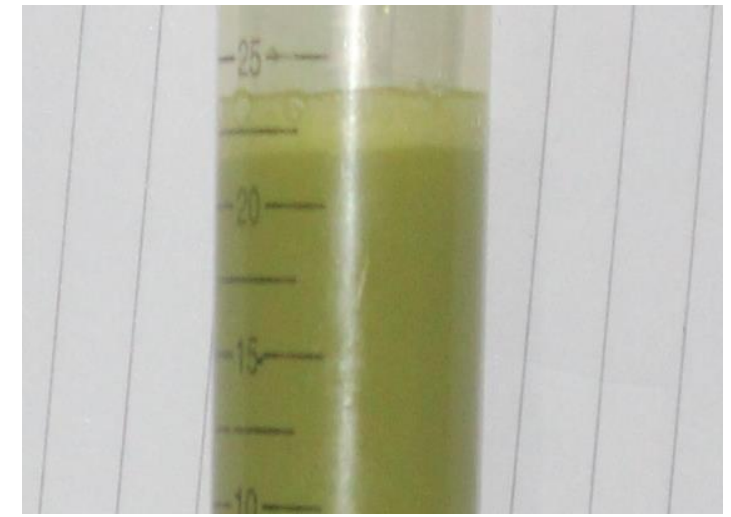

Positive (b)

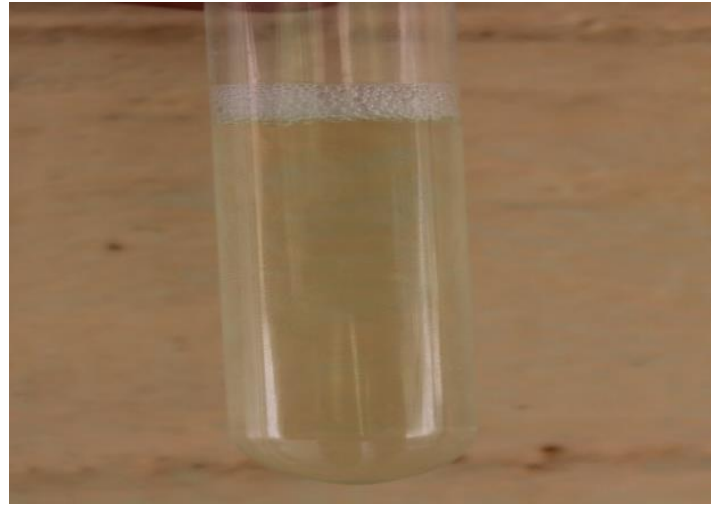

Positive

Figure 5. Saponin Test of (a) chloroform (Positive) and (b) ethanolic (Positive) extracts

(a)

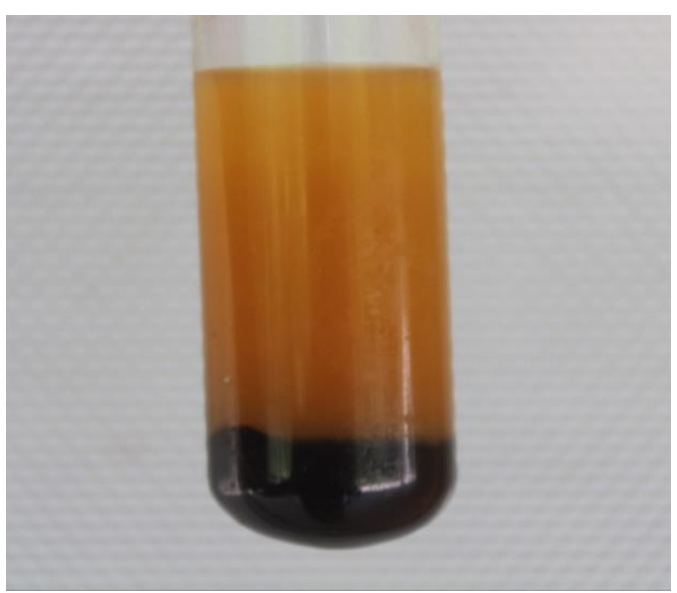

(b)

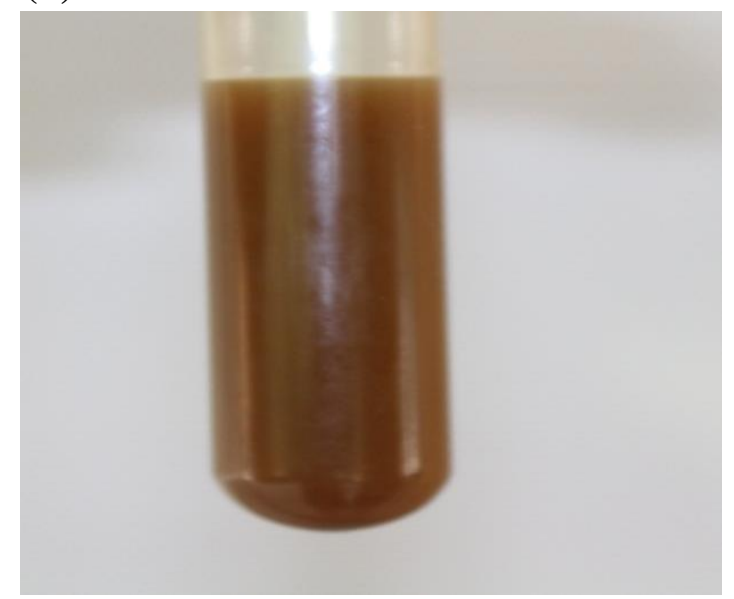

Figure 6. Tanins Test of (a) chloroform (Positive) and (b) ethanolic (Negative) extracts 
(a)

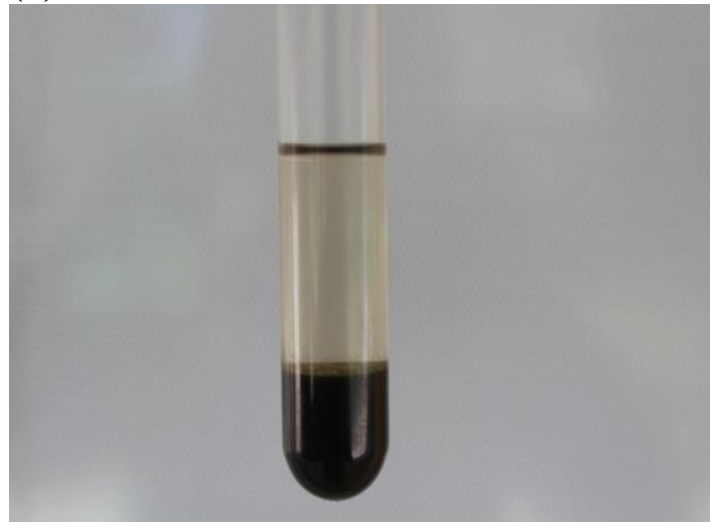

Negative

Figure 7. Cardiac glycoside Test of (a) chloroform (Negative) and (b) ethanolic (Positive) extracts (b)

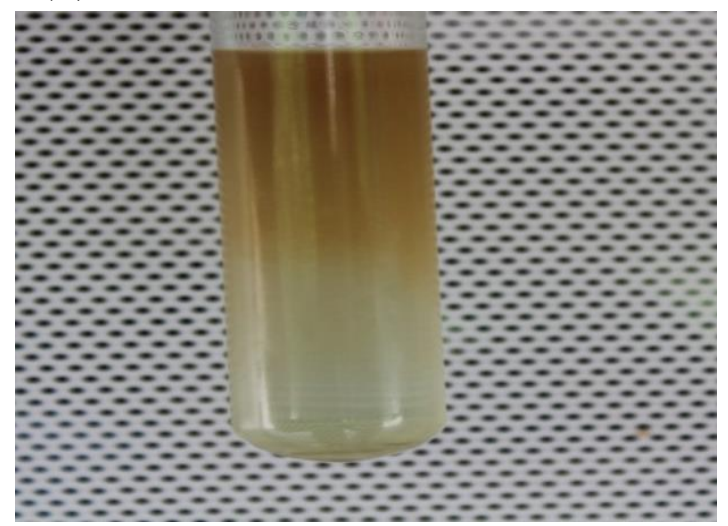

Positive

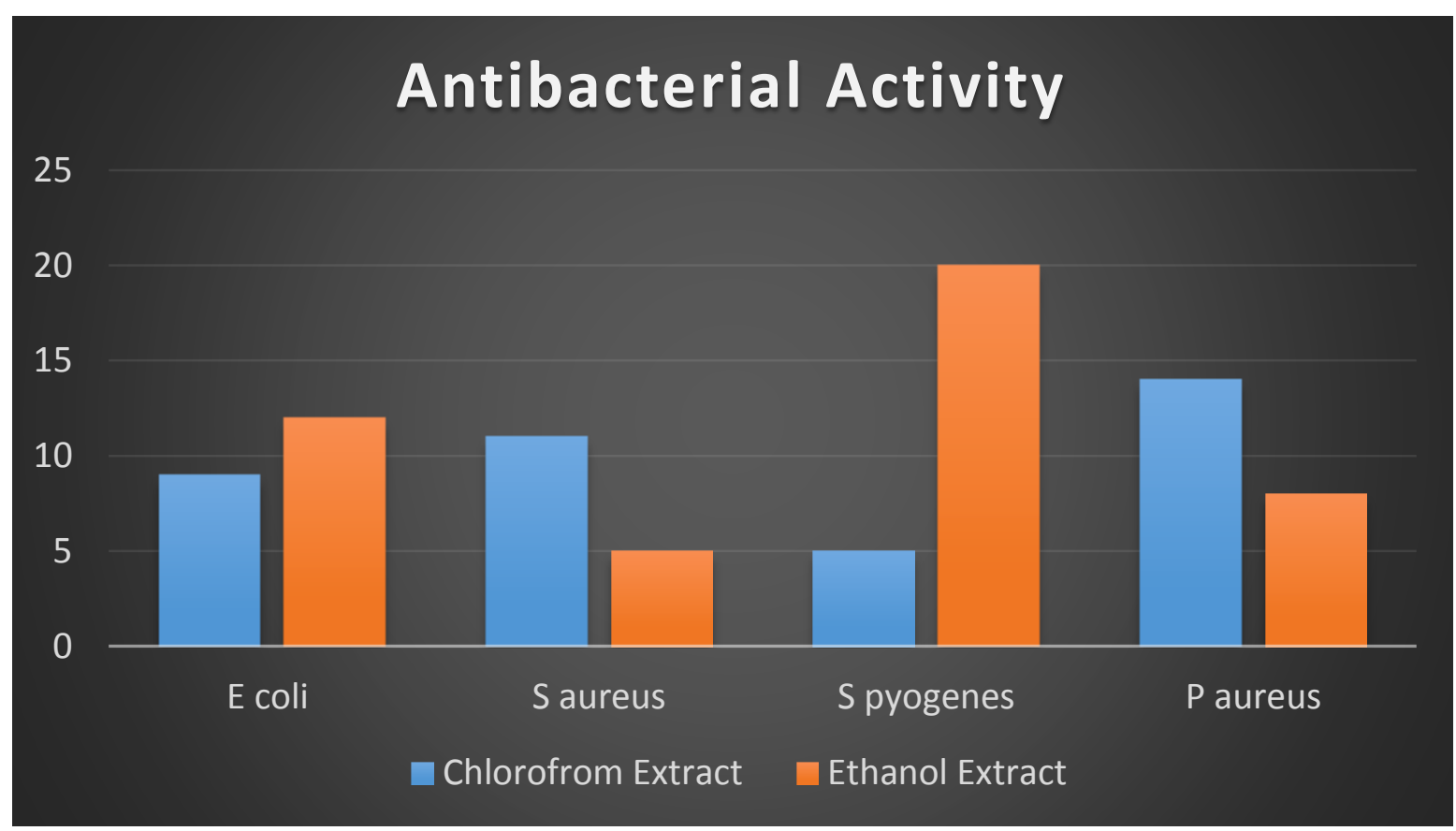

Figure 8. Antibacterial activity of chloroform and ethanolic extracts of $A$. Vasica leaves
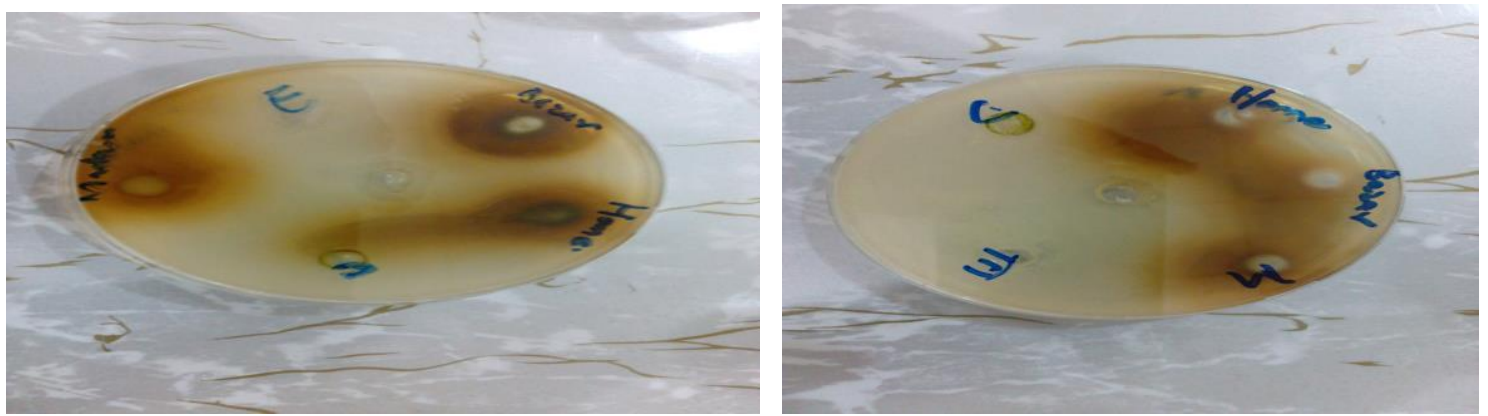

Figure 9. Antibacterial zone of chloroform and ethanolic extracts of $A$. Vasica leaves against $E$. coli $(\mathrm{L})$ and $S$. aureus (R) 

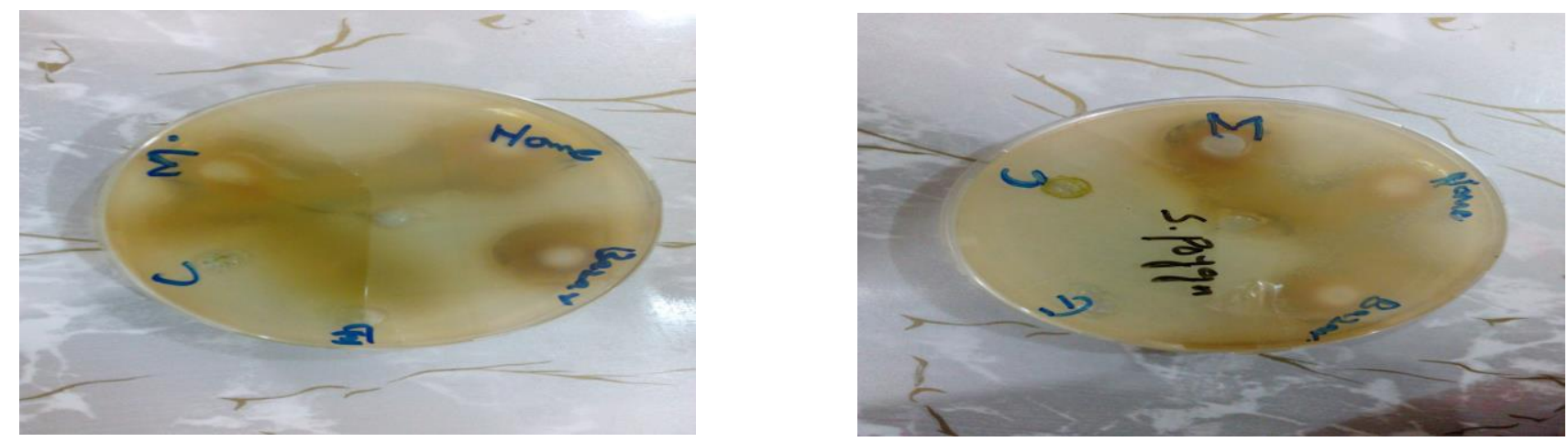

Figure 10. Antibacterial zone of chloroform and ethanolic extracts of $A$. Vasica leaves against $P$. aureus $(\mathrm{L})$ and $S$. pyogenes $(\mathrm{R})$

\section{Conclusion}

The current study was aimed at the evaluation of A. vasica leaf extracts for phytochemical profiling along with their antibacterial potential. The results showed promising indication of presence of phytochemicals like steroids, flavonoids, terpenoids, tannins and Saponins except alkaloids and cardiac glycodides in the chloroform extracts. While lacks in steroids and terpenoids. Both of the extracts showed antibacterial activity against E. coli, S. aureus and S. pyogenes, however, ethanolic extracts exhibited maximum activity against $E$. coli and $S$. aureus and can be used in varoious food, pharmaceutical and cosmetic products.

\section{Authors' contributions}

Conceived and designed the experiments: Q Shahzad \& S Sammi, Performed the experiments: Q Shahzad \& Q Ayub, Analyzed the data: A Mehmood \& M Hussain, Contributed materials/ analysis/ tools: K Naveed, K Azeem, M Hassaan \& A Ayub, Wrote the paper: A Mehmood \& O Shokat.

\section{References}

1. Pham-Huy LA, He H \& Pham-Huy C (2008). Free radicals, antioxidants in disease and health. Inter $J$ of Biomed Sci 4(2): 89.

2. Mishra A, Kumar S, Bhargava A, Sharma B \& Pandey AK (2011). Studies on in vitro antioxidant and antistaphylococcal activities of some important medicinal plants. Cellular \& Mol Biol 57(1): 16-25.

3. Maurya S \& Singh D (2010). Quantitative analysis of total phenolic content in Adhatoda vasica, Nees extracts. Inter $J$ of Pharm Tech Res 2(4): 2403-2406.

4. Rajurkar NS, Gaikwad KN \& Razavi MS (2012). Evaluation of free radical scavenging activity of Justicia adhatoda: a gamma radiation study. Inter $J$ of Pharm and Pharmace Sci 4(Suppl 4): 93-96.

5. Mamta P \& Sujata B (2013). Rachana. Antioxidant activity and cytoprotective potential of ethanolic extract of Adhatoda vasica. Inter $J$ of Pharm Tech Res 5(2).

6. Wankhede TB (2015). Antioxidant and antimicrobial properties of Adhatoda vasica L. Nees. Inter $J$ of Life Sci 3(2): 152-156.

7. Kumar M, Dandapat S, Kumar A \& Sinha MP (2014). Pharmacological screening of leaf extract of Adhatoda vasica for therapeutic efficacy. Global $J$ of Pharmacol 8(4): 494-500.

8. Ahmed W, Azmat R, Khan SU, Khan SM, Liaquat M, Qayyum A \& Mehmood A (2018). Pharmacological studies of isolated compounds from Adhatoda vasica and Calotropis procera as an antioxidant and antimicrobial bioactive sources. Pak $J$ of Bot 50(6): 2363-2367. 
9. Godghate A \& Sawant R (2013). Qualitative phytochemical analysis of chloroform extract of leaves of Adhatoda vasica.Rasayan $J$ of Chem 6: 107-110.

10. Egwaikhide PA \& Gimba CE (2007). Analysis of the phytochemical content and anti-microbial activity of Plectranthus glandulosis whole plant. Middle-East J of Sci Res 2(3-4): 135138.

11. Edeoga HO, Okwu DE \& Mbaebie BO (2005). Phytochemical constituents of some Nigerian medicinal plants. Afr $J$ of Biotechnol 4(7): 685-688.

12. Adebayo EA, Ishola OR, Taiwo OS, Majolagbe ON \& Adekeye BT (2009). Evaluations of the methanol extract of Ficus exasperata stem bark, leaf and root for phytochemical analysis and antimicrobial activities. Afr J of Plant Sci 3(12): 283-287.

13. Bauer AW. Antibiotic susceptibility testing by a standardized single disc method". American J of Clin Pathol 45(4): 493-496.

14. Karthikeyan A, Shanthi V \& Nagasathaya A (2009). Preliminary phytochemical and antibacterial screening of crude extract of the leaf of Adhatoda vasica. L. Inter $J$ of Green Pharm 3(1).
15. Kurek J (2009). Alkaloids: Their importance in Nature and Human life. Intechopen Ltd. London. UK.

16. Yarkowska D (2019). Plants are capable of synthesizing animal steroid hormones. Mol 24(14): 2585.

17. Singh AP \& Kumar S (2019). Application of tannins in industry. Intechopen Ltd. London. UK.

18. Pandit K \& Langfield RD (2004). Antibacterial activity of some Italian medicinal plant. $J$ of Ethnopharmacol 82: 135-142.

19. Nnama TN, Asomugha AL, Asomugha RN, Umeasalugo KE \& Mgbemena IO (2017). Phytochemical Analysis and Acute Toxicological Study of Erythrina senegalensis Ethanolic Leaf Extract in Albino Wistar Rats. $J$ of Anot and Physiol 7(248): 2161-0940.

20. Karthikeyan A, Shanthi V \& Nagasathaya A (2009). Preliminary phytochemical and antibacterial screening of crude extract of the leaf of Adhatoda vasica. L. Inter $J$ of Green Pharm 3(1): 78-80.

21. Ignacimuthu, S., \& Shanmugam, N. (2010). Antimycobacterial activity of two natural alkaloids, vasicine acetate and 2-acetyl benzylamine, isolated from Indian shrub Adhatoda vasica Ness. leaves. $J$ of Biosci 35(4): 565570. 